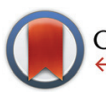

CrossMark \&lick for update

Cite this: Org. Chem. Front., 2015, 2 236

Received 26th November 2014, Accepted 20th January 2015

DOI: $10.1039 / c 4 q 000312 h$

rsc.li/frontiers-organic

\section{Selective syntheses of leuconolam, leuconoxine, and mersicarpine alkaloids from a common intermediate through regiocontrolled cyclizations by Staudinger reactions $\uparrow$}

\author{
Zining Li, ${ }^{a}$ Qian Geng, ${ }^{a}$ Zhe Lv, $^{a}$ Beau P. Pritchett, ${ }^{\text {b Katsuaki Baba, }}{ }^{b}$ \\ Yoshitaka Numajiri, ${ }^{\mathrm{b}}$ Brian M. Stoltz* ${ }^{\star \mathrm{b}}$ and Guangxin Liang*a
}

Selective syntheses of leuconolam, leuconoxine, and mersicarpine alkaloids bearing distinctive core structures were achieved through Staudinger reactions using a common intermediate. In the key cyclization step, water functioned like a switch to control which core structure to produce. The chemistry allowed for selective syntheses of the group of alkaloids from a simple intermediate through straightforward chemical operations.

\section{Introduction}

Leuconolam, leuconoxine, and mersicarpine alkaloids showcase the incredible structural diversity of natural products. These monoterpene indole alkaloid families, though sharing the same biogenetic origin, ${ }^{1}$ present distinctive skeletons with three completely different polycyclic patterns (1-6, Fig. 1).

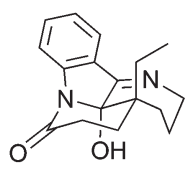

1: mersicarpine

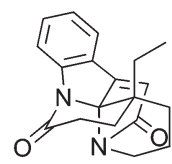

4: melodinine $\mathrm{E}$

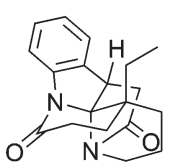

2: leuconoxine

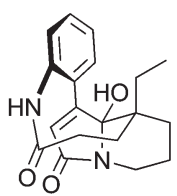

5: leuconolam

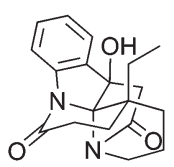

3: leuconodine B

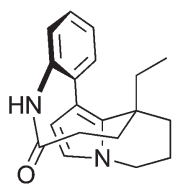

6: rhazinilam
Fig. 1 Representative biosynthetically related monoterpene indole alkaloids with distinctive skeleton diversity.

\footnotetext{
${ }^{a}$ State Key Laboratory and Institute of Elemento-organic Chemistry, Collaborative Innovation Center of Chemical Science and Engineering (Tianjin), Nankai University, Tianjin 300071, China.E-mail: lianggx@nankai.edu.cn

${ }^{b}$ The Warren and Katharine Schlinger Laboratory of Chemistry and Chemical Engineering, Division of Chemistry and Chemical Engineering, California Institute of Technology, Pasadena, California 91125,USA.E-mail: stoltz@caltech.edu $\dagger$ Electronic supplementary information (ESI) available: Experimental details and procedures, compound characterization data, copies of ${ }^{1} \mathrm{H}$ and ${ }^{13} \mathrm{C}$ NMR spectra for new compounds. See DOI: 10.1039/c4qo00312h
}

Mersicarpine (1), isolated from both Kopsia and Leuconotis species of plants by Kam and co-workers, ${ }^{2}$ features a sevenmembered cyclic imine, a $\delta$-lactam, and an all-carbon quaternary center around a fully substituted hemiaminal stereogenic center. Although leuconoxine (2), ${ }^{3}$ leuconodine B (3), ${ }^{4}$ and melodinine $\mathrm{E}(\mathbf{4})^{5}$ hold the same $\delta$-lactam and indoline moiety as mersicarpine, different bond connections and two additional carbons create an entirely new skeleton distinguished by an aminal functionality, a piperidine ring, and an extra $\gamma$-lactam. Leuconolam $(5)^{6}$ and rhazinilam $(6)^{7}$ possess an unusual nine-membered lactam and a pyrrole derived-unit. It is proposed that leuconolam is a biosynthetic precusor of melodinine E, which further produces mersicarpine via a skeletal rearrangement and subsequent loss of two carbons in the form of acetic acid. ${ }^{2 a}$ The intriguing structural features and biosynthetic connections of these alkaloids make them appealing synthetic targets. ${ }^{8}$ To date, eight syntheses of mersicarpine $^{9}$ and three syntheses of leuconoxine-type alkaloids have been reported. ${ }^{9 e, g, 10}$ Leuconolam has been accessed through both total synthesis ${ }^{9 e, g, 11}$ and oxidative conversion from rhazinilam. ${ }^{12}$ Rhazinilam has been the focus of numerous synthetic efforts. ${ }^{9 g, 13}$

Throughout our efforts toward the total synthesis of mersicarpine, ${ }^{9 f, 14}$ we became increasingly interested in its connections with leuconolam and leuconoxine alkaloids. We envisioned rapid access to all three different polycyclic patterns through a versatile intermediate 7 (Scheme 1). Leuconolam (5) could be obtained through disconnection of the $\mathrm{C}-\mathrm{N}$ bond of melodinine E (4). Melodinine E could be accessed from 11 by an acetylation and aldol condensation sequence. Given that mersicarpine (1) and $\mathbf{1 1}$ have the same oxidation 


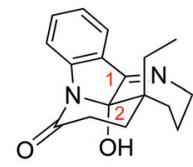

mersicarpine (1)

$\Downarrow$
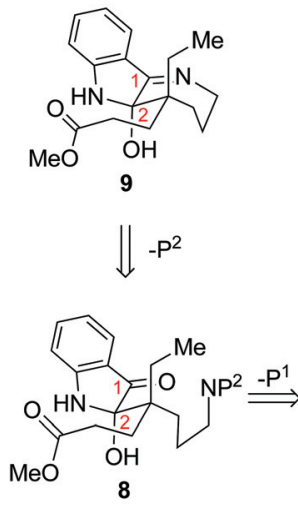

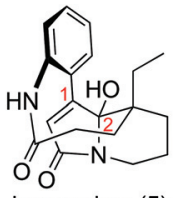

leuconolam (5)

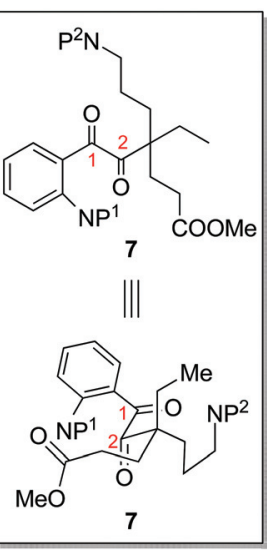

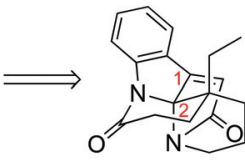

melodinine $\mathrm{E}(\mathbf{4})$

$\Downarrow$
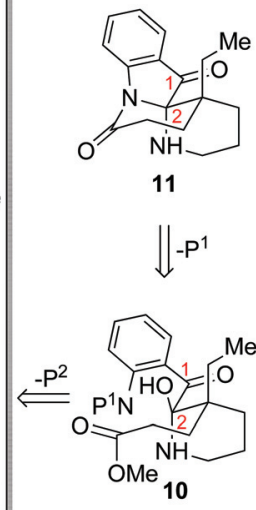

Scheme 1 Initial synthetic design of different cyclization sequences leading to distinct molecular skeletons.

state but different bond connections, we conceived that both compounds could be prepared from a common acyclic intermediate 7 through divergent cyclization sequences. We aimed to take advantage of orthogonal protecting groups $\mathrm{P}^{1}$ and $\mathrm{P}^{2}$ on the aniline and amine nitrogens, respectively. Upon the removal of $\mathrm{P}^{1}$, facile hemiaminal formation at the $\mathrm{C} 2$ position would afford $\mathbf{8}$, which could in turn produce compound $\mathbf{9}$ upon removal of $\mathrm{P}^{2}$. If instead $\mathrm{P}^{2}$ is removed first, a more favourable 6-membered hemiaminal formation would generate intermediate 10, which could produce compound $\mathbf{1 1}$ following $\mathrm{P}^{1}$ removal and subsequent lactam formation. It is worth noting that Zhu and co-workers applied a similar strategy in their recent syntheses of these alkaloids, in which they used fine-tuned hydrogenation conditions to control the cyclization sequences. ${ }^{9 e}$ Herein, we report a new approach to three different classes of alkaloids using Staudinger reaction as a key ring formation step from a common acyclic intermediate.

\section{Results and discussion}

In the forward synthesis, we chose compound $\mathbf{1 6}$ (Scheme 2) to be a preferred intermediate with a Boc-protected aniline $\left(\mathrm{NP}^{1}\right)$ and an azide $\left(\mathrm{NP}^{2}\right)$ as a masked amine to enable differentiable deprotection. Our quick construction of 16 commenced from a known compound 12. ${ }^{15}$ Hydroborationoxidation, ${ }^{16}$ followed by a Mitsunobu reaction using DPPA $^{17}$ converted 12 to compound $\mathbf{1 3}$ featuring a primary azide. Lactol formation was effected with DIBAL-H, followed by Ohira-Bestmann homologation ${ }^{18}$ afforded alkyne 14. Oxidation of the primary alcohol, followed by Fischer esterification provided the desired coupling partner for Sonogashira coupling ${ }^{19}$ with tert-butyl-(2-iodophenyl) carbamate to furnish 15 in good yield. Ruthenium-catalysed oxidation ${ }^{20}$ of the alkyne afforded 1,2-diketone 16 in 66\% yield.

We then turned our attention to exploring divergent cyclization sequences involving 1,2-diketone 16 (Scheme 3). To our surprise, compound 17 didn't undergo spontaneous hemiaminal formation, but was isolated in $69 \%$ yield following selective removal of the Boc group in 16 with TMSOTf in the presence of 2,6-lutidine. ${ }^{21}$ However, treatment of 17 with triphenylphosphine in a mixed solvent of THF and water cleanly furnished mersicarpine in $66 \%$ yield. This remarkably simple reaction forms the three remaining rings in mersicarpine

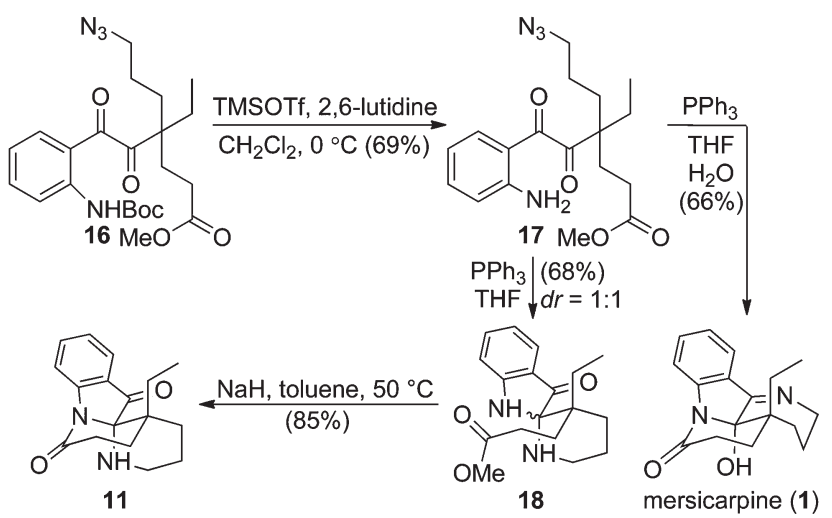

Scheme 3 Selective syntheses of mersicarpine and the core structure 11 in leuconoxine-type alkaloids.

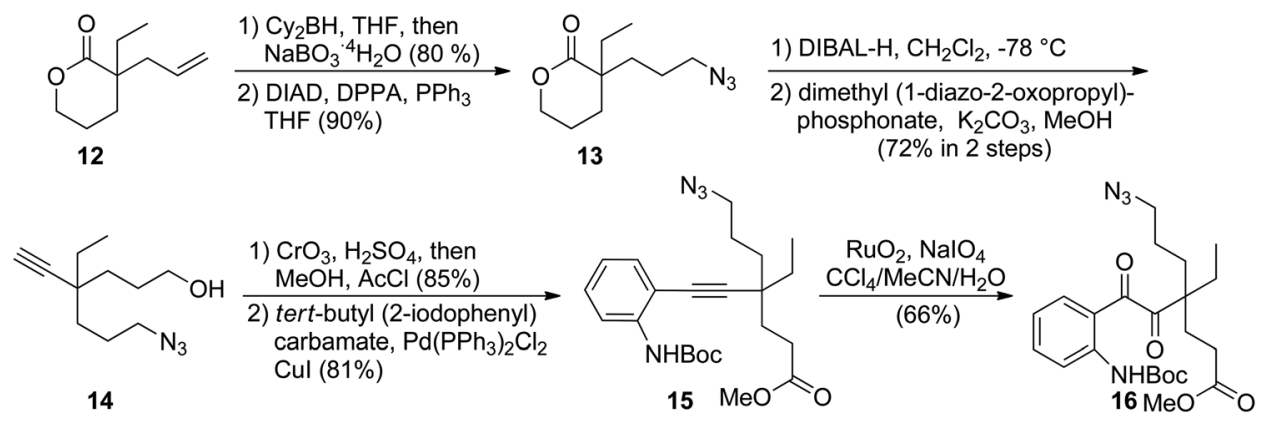

Scheme 2 Preparation of the common intermediate 16. 
under mild conditions. Notably, the oxidation states of diketone in $\mathbf{1 7}$ were exploited to rapidly arrive at the target in a redox-free manner. Importantly, a Staudinger reaction in the absence of water gave an inseparable diastereomeric mixture of compound 18, which possesses a totally different polycyclic framework. We hypothesize that an aza-Wittig pathway is operative in the absence of water. ${ }^{22}$ In the event, the more favourable 6-membered imine is formed, followed by aminal formation with no facial selectivity. Impressively, when a diastereomeric mixture of $\mathbf{1 8}$ was treated with sodium hydride in toluene at $50{ }^{\circ} \mathrm{C}$, compound 11 was generated in $85 \%$ yield. This finding indicates that an interconversion of the two diastereomeric aminals formed under the reaction conditions funnels the mixture toward a thermodynamically favored product (11).

Key intermediate $\mathbf{1 1}$ facilitated completion of the total syntheses of three leuconoxine-type alkaloids as well as leuconolam (Scheme 4). Acetylation of the free amine in the piper-
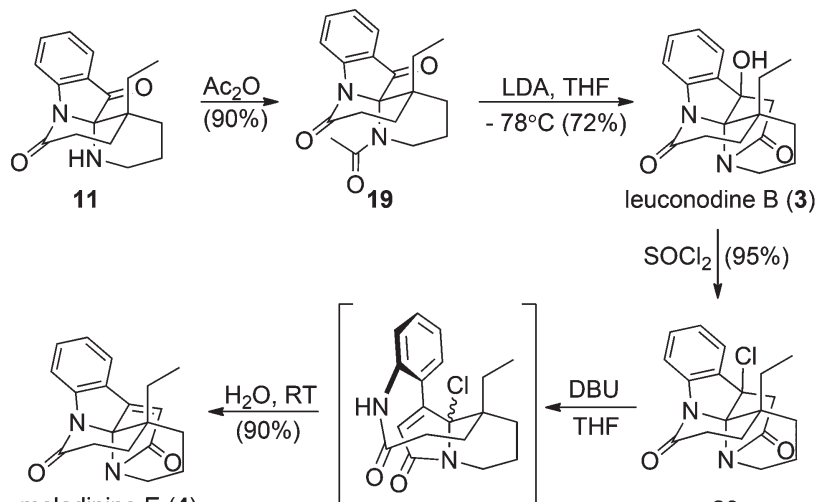

melodinine $\mathrm{E}(\mathbf{4})$
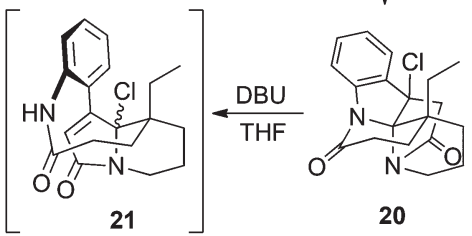

$\mathrm{H}_{2}(4 \mathrm{~atm})$ $\mathrm{Pd} / \mathrm{C}, \mathrm{EtOAc}$ $(99 \%)$

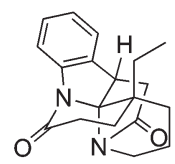

leuconoxine (2)

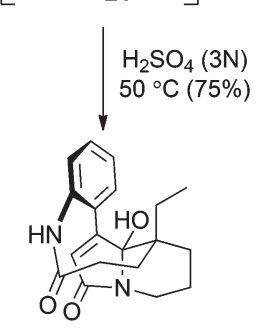

leuconolam (5)

Scheme 4 Syntheses of leuconodine B, melodinine E, leuconoxine, and leuconolam.

idine ring in $\mathbf{1 1}$ proceeded smoothly in neat acetic anhydride at room temperature to afford 19. When treated with LDA at $-78{ }^{\circ} \mathrm{C}, 19$ produced leuconodine B readily in $72 \%$ yield. The transformation of leuconodine $\mathrm{B}$ to melodinine $\mathrm{E}$ was fulfilled in $90 \%$ yield upon treatment with neat thionyl chloride at room temperature followed by elimination with DBU in THF and subsequent aqueous workup. Initially, we believed that treatment of $\mathbf{2 0}$ with DBU would generate melodinine $\mathrm{E}$ directly, but surprisingly melodinine E was not detected by ${ }^{1} \mathrm{H}$ NMR spectroscopy in the crude mixture without an aqueous workup. The major product was too sensitive to be isolated and attempted purification of this compound with column chromatography produced melodinine E. High resolution mass spectrometry data suggest that treatment of $\mathbf{2 0}$ with DBU yields the proposed structure 21. When the sensitive intermediate 21 was stirred in water at room temperature, melodinine $\mathrm{E}$ was produced in $90 \%$ yield. Interestingly, when 21 was treated with an aqueous solution of $3 \mathrm{~N} \mathrm{H}_{2} \mathrm{SO}_{4}$ at $50{ }^{\circ} \mathrm{C}$, leuconolam was generated in $75 \%$ yield. Using conditions reported by Zhu and co-workers, leuconolam can also be prepared directly from melodinine E. ${ }^{9 e}$ Finally, hydrogenation on melodinine E occurred efficiently to generate leuconoxine in nearly quantitative yield.

With efficient racemic syntheses in hand, we took on an effort to produce optically active 12, thereby achieving formal asymmetric syntheses of these alkaloids (Scheme 5). Initially, we hoped diester 22 could undergo an efficient asymmetric allylic alkylation to construct enantioenriched quaternary lactone 23. We found that the reaction with diester 22 proceeded smoothly, but with disappointing enantioselectivity ( $81 \%$ ee). Eventually, we were able to generate optically active 12 from an $N$-benzyloxy imide 24 , which could be readily prepared in $80 \%$ yield and $98 \%$ ee. ${ }^{23}$ Reduction of 24 with an excess of $\mathrm{NaBH}_{4}$ formed hydroxamic acid 25 with the desired free primary alcohol. The following acid-induced cyclization of 25 provided the desired lactone (-)-12 in 54\% yield over 2 steps.

\section{Conclusions}

In summary, we have completed total syntheses of mersicarpine (1), leuconoxine (2), leuconodine (3), melodinine E (4),

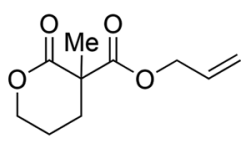

22

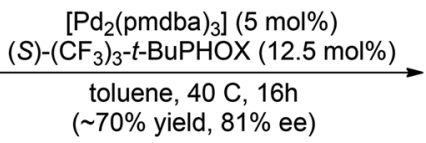

( $70 \%$ yield, $81 \%$ ee)

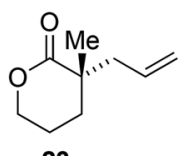

23

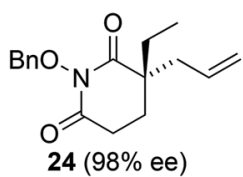

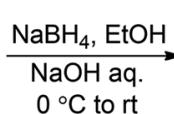

$0{ }^{\circ} \mathrm{C}$ to $\mathrm{rt}$

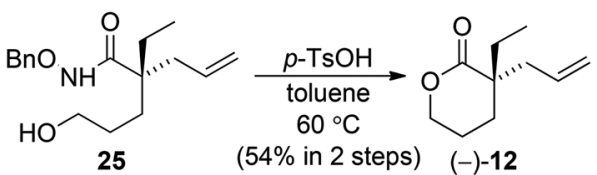

Scheme 5 Efforts in preparing optically active 12 
and leuconolam (5) by controlling specific cyclization sequences through a key Staudinger reaction to access different polycyclic frameworks. Additionally, we have achieved enantioselective formal syntheses of these alkaloids by synthesizing enantioenriched lactone 12 via an asymmetric allylic alkylation, reduction, and cyclization sequence.

\section{Acknowledgements}

The NKU authors thank the National Natural Science Foundation of China, Tianjin Natural Science Foundation (grant no. 12JCZDJC26400), the '111' project (B06005) of the Ministry of Education of China, and Program for New Century Excellent Talents in University for financial support. The Caltech authors wish to thank NIH-NIGMS (R01GM080269) for financial support. BPP is grateful to the National Science Foundation for a Graduate Research Fellowship. Toray is thanked for providing YN a postdoctoral opportunity at Caltech.

\section{Notes and references}

1 (a) S. H. Goh and A. R. M. Ali, Tetrahedron Lett., 1986, 27, 2501-2504; (b) J. Hájíček, Collect. Czech. Chem. Commun., 2011, 76, 2023-2083; (c) M. Ishikura, T. Abe, T. Choshi and S. Hibino, Nat. Prod. Rep., 2013, 30, 694-752; (d) Y.-Y. Low, F.-J. Hong, K.-H. Lim, N. F. Thomas and T.-S. Kam, J. Nat. Prod., 2014, 77, 327-338.

2 (a) T.-S. Kam, G. Subramaniam, K.-H. Lim and Y.-M. Choo, Tetrahedron Lett., 2004, 45, 5995-5998; (b) C.-Y. Gan, Y.-Y. Low, N. F. Thomas and T.-S. Kam, J. Nat. Prod., 2013, 76, 957-964.

3 F. Abe and T. Yamauchi, Phytochemistry, 1994, 35, 169171.

4 (a) T. Feng, X.-H. Cai, P.-J. Zhao, Z.-Z. Du, W.-Q. Li and X.-D. Luo, Planta Med., 2009, 75, 1537-1541; (b) C.-Y. Gan, Y.-Y. Low, N. F. Thomas and T.-S. Kam, J. Nat. Prod., 2013, 76, 957-964.

5 T. Feng, X.-H. Cai, Y.-P. Liu, Y. Li, Y.-Y. Wang and X.-D. Luo, J. Nat. Prod., 2010, 73, 22-26.

6 S. H. Goh, C. Wei and A. R. M. Ali, Tetrahedron Lett., 1984, 25, 3483-3484.

7 (a) H. H. A. Linde, Helv. Chim. Acta, 1965, 48, 1822-1842; (b) A. Banerji, P. L. Majumder and A. Chatterjee, Phytochemistry, 1970, 9, 1491-1493; (c) D. J. Abraham, R. D. Rosenstein, R. L. Lyon and H. H. S. Fong, Tetrahedron Lett., 1972, 13, 909-912.

8 For selected syntheses of other alkaloids bearing dearomatized indole moiety, see: (a) S. Han and M. Movassaghi, J. Am. Chem. Soc., 2011, 133, 10768-10771; (b) X. Zhang, T. Mu, F. Zhan, L. Ma and G. Liang, Angew. Chem., Int. Ed., 2011, 50, 6164-6166; (c) F. Zhan and G. Liang, Angew. Chem., Int. Ed., 2013, 52, 1266-1269; (d) S. Li, J. Han and A. Li, Acta Chim. Sin., 2013, 71, 295-298; (e) Y. Sun, R. Li,
W. Zhang and A. Li, Angew. Chem., Int. Ed., 2013, 52, 92019204; $(f)$ Y. Sun, P. Chen, D. Zhang, M. Baunach, C. Hertweck and A. Li, Angew. Chem., Int. Ed., 2014, 53, 9012-9016.

9 For total syntheses of mersicarpine, see: (a) J. Magolan, C. A. Carson and M. A. Kerr, Org. Lett., 2008, 10, 14371440; (b) R. Nakajima, T. Ogino, S. Yokoshima and T. Fukuyama, J. Am. Chem. Soc., 2010, 132, 1236-1237; (c) Y. Iwama, K. Okano, K. Sugimoto and H. Tokuyama, Org. Lett., 2012, 14, 2320-2322; (d) Y. Iwama, K. Okano, K. Sugimoto and H. Tokuyama, Chem. - Eur. J., 2013, 19, 9325-9334; (e) Z. Xu, Q. Wang and J. Zhu, J. Am. Chem. Soc., 2013, 135, 19127-19130; $(f)$ Z. Lv, Z. Li and G. Liang, Org. Lett., 2014, 16, 1653-1655; (g) Y. Yang, Y. Bai, S. Sun and M. Dai, Org. Lett., 2014, 16, 6216-6219. For the formal total syntheses of mersicarpine, see: $(h)$ A. Biechy and S. Z. Zard, Org. Lett., 2009, 11, 2800-2803; (i) X. Zhong, Y. Li and F.-S. Han, Chem. - Eur. J., 2012, 18, 9784-9788.

10 A. Umehara, H. Ueda and H. Tokuyama, Org. Lett., 2014, 16, 2526-2529.

11 (a) M. G. Banwell, D. A. S. Beck and A. C. Willis, ARKIVOC, 2006 (no. iii), 163-174; (b) E. C. Izgu and T. R. Hoye, Chem. Sci., 2013, 4, 2262-2266.

12 A. Décor, D. Bellocq, O. Thoison, N. Lekieffre, A. Chiaroni, J. Ouazzani, T. Cresteil, F. Guéritte and O. Baudoin, Bioorg. Med. Chem., 2006, 14, 1558-1564.

13 For representative total syntheses of rhazinilam, see: (a) A. H. Ratcliffe, G. F. Smith and G. N. Smith, Tetrahedron Lett., 1973, 14, 5179-5184; (b) P. Magnus and T. Rainey, Tetrahedron, 2001, 57, 8647-8651; (c) J. A. Johnson and D. Sames, J. Am. Chem. Soc., 2000, 122, 6321-6322; (d) J. A. Johnson, N. Li and D. Sames, J. Am. Chem. Soc., 2002, 124, 6900-6903; (e) A. L. Bowie, C. C. Hughes and D. Trauner, Org. Lett., 2005, 7, 5207-5209; (f) Z. Liu, A. S. Wasmuth and S. G. Nelson, J. Am. Chem. Soc., 2006, 128, 10352-10353; $(g)$ A. L. Bowie and D. Trauner, J. Org. Chem., 2009, 74, 1581-1586; (h) Z. Gu and A. Zakarian, Org. Lett., 2010, 12, 4224-4227; (i) L. McMurray, E. M. Beck and M. Gaunt, Angew. Chem., Int. Ed., 2012, 51, 9288-9291; (j) J.-B. Gualtierotti, D. Pasche, Q. Wang and J. Zhu, Angew. Chem., Int. Ed., 2014, 53, 9926-9930.

14 Z. Li and G. Liang, Tetrahedron Lett., 2013, 54, 242-244.

15 J. L. Herrmann and R. H. Schlessinger, J. Chem. Soc., Chem. Commun., 1973, 711-712.

16 H. C. Brown and B. C. S. Rao, J. Am. Chem. Soc., 1956, 78, 5694-5695.

17 (a) B. Lal, B. N. Pramanik, M. S. Manhas and A. K. Bose, Tetrahedron Lett., 1977, 18, 1977-1980; (b) Z. Xu, Q. Wang and J. Zhu, Angew. Chem., Int. Ed., 2013, 52, 3272-3276.

18 (a) S. Müller, B. Liepold, G. J. Roth and H. J. Bestmann, Synlett, 1996, 521-522; (b) G. J. Roth, B. Liepold, S. G. Müller and H. J. Bestmann, Synthesis, 2004, 59-62.

19 (a) K. Sonogashira, Y. Tohda and N. Hagihara, Tetrahedron Lett., 1975, 16, 4467-4470; (b) C. C. Li, Z. X. Xie, Y. D. Zhang, J. H. Chen and Z. Yang, J. Org. Chem., 2003, 68, 8500-8504. 
20 (a) R. Zibuck and D. Seebach, Helv. Chim. Acta, 1988, 71, 237-240; (b) M. F. Semmelhack, S. R. Campagna, M. J. Federle and B. L. Bassler, Org. Lett., 2005, 7, 569-572.

21 H. M. M. Bastiaans, J. L. van der Baan and H. C. J. Ottenheijm, J. Org. Chem., 1997, 62, 3880-3889.

22 For recent reviews on $A z a$-Wittig reactions, see: (a) S. Eguchi, Y. Matsushita and K. Yamashita, Org. Prep.
Proced. Int., 1992, 24, 209-243; (b) P. M. Fresneda and P. Molina, Synlett, 2004, 1-17.

23 (a) D. C. Behenna, Y. Liu, T. Yurino, J. Kim, D. E. White, S. C. Virgil and B. M. Stoltz, Nat. Chem., 2012, 4, 130-133; (b) N. B. Bennett, D. C. Duquette, J. Kim, W.-B. Liu, D. C. Behenna, S. C. Virgil and B. M. Stoltz, Chem. - Eur. J., 2013, 19, 4414-4418. 